\title{
Regional gray matter correlates of vocational interests
}

\author{
David H Schroeder ${ }^{1 *}$, Richard J Haier ${ }^{2}$ and Cheuk Ying Tang $^{3}$
}

\begin{abstract}
Background: Previous studies have identified brain areas related to cognitive abilities and personality, respectively. In this exploratory study, we extend the application of modern neuroimaging techniques to another area of individual differences, vocational interests, and relate the results to an earlier study of cognitive abilities salient for vocations.

Findings: First, we examined the psychometric relationships between vocational interests and abilities in a large sample. The primary relationships between those domains were between Investigative (scientific) interests and general intelligence and between Realistic ("blue-collar") interests and spatial ability. Then, using MRI and voxelbased morphometry, we investigated the relationships between regional gray matter volume and vocational interests. Specific clusters of gray matter were found to be correlated with Investigative and Realistic interests. Overlap analyses indicated some common brain areas between the correlates of Investigative interests and general intelligence and between the correlates of Realistic interests and spatial ability.

Conclusions: Two of six vocational-interest scales show substantial relationships with regional gray matter volume. The overlap between the brain correlates of these scales and cognitive-ability factors suggest there are relationships between individual differences in brain structure and vocations.
\end{abstract}

\section{Findings}

A growing number of neuroimaging studies focus on individual differences in mental abilities. There are now many studies of the general factor of intelligence $(g)$ (see reviews by Jung \& Haier [1] and Deary et al. [2]) and specific intelligence factors (e.g., [3,4]). Jung and Haier [1] introduced the Parieto-Frontal Integration Theory, or P-FIT, specifically to account for the neuroimaging findings regarding general intelligence. There are also many imaging studies of personality (see review by Haier [5] and also DeYoung et al. [6]).

One area of individual differences that has not been studied with neuroimaging techniques is vocational interests. Individuals show wide variation on multiple dimensions of interests, and these differences have important implications for career choice [7]. Interests are also related to abilities [8] and to personality [9], and since those domains are related to brain differences, it is

\footnotetext{
* Correspondence: schroeder@jocrf.org

'Johnson O'Connor Research Foundation, Chicago, IL, USA

Full list of author information is available at the end of the article
}

possible that vocational interests will also show meaningful relationships with the brain.

The most widely used and empirically studied model of vocational interests was developed by Holland [7]. As summarized in Table 1, Holland's hexagon model incorporates six interest areas: Realistic, Investigative, Artistic, Social, Enterprising, and Conventional. As shown in Figure 1, the hexagon structure corresponds to the relationships among the six areas: Enterprising interests are most closely related to Social and Conventional interests and least related to Investigative interests, Realistic interests are most related to Conventional and Investigative interests and least related to Social interests, and so on.

Recently, we reported relationships between regional gray matter and mental abilities specifically related to vocations, along with white matter correlates, using a battery of tests developed by the Johnson O'Connor Research Foundation $[11,12]$. Here we report on gray matter correlates of vocational interests in the same sample. This allows a direct comparison of the gray matter correlates for vocational interests with the correlates for ability dimensions related to vocations.

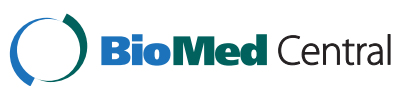

(c) 2012 Schroeder et al.; licensee BioMed Central Ltd. This is an Open Access article distributed under the terms of the Creative Commons Attribution License (http://creativecommons.org/licenses/by/2.0), which permits unrestricted use, distribution, and reproduction in any medium, provided the original work is properly cited. 
Table 1 Scales on the self-directed search

\begin{tabular}{lll}
\hline Scale & Reliability & Description \\
\hline Realistic & .92 & Interest in outdoor, hands-on activities that involve tangible objects. \\
Investigative & .93 & Interest in scientific work. \\
Artistic & .92 & Interest in artistic endeavors of various types such as visual art, music, and writing. \\
Social & .92 & Interest in social interaction, often in human-service contexts. \\
Enterprising & .93 & Interest in social interaction in a context of selling and/or persuasion. \\
Conventional & .93 & Interest in highly structured activities including clerical and \\
& & administrative functions.
\end{tabular}

Note. The reliability coefficients are averages of the internal-consistency reliabilities for adult males and females, respectively, given in the SDS technical manual p. $22[10]$.

Based on Holland's model, we tested specific hypotheses regarding two of his scales:

1. Because vocational interests in the Investigative area are related to general intelligence $(g)$ [13], we hypothesized that Investigative interests would show similar brain correlates to $g$ [1].

2. Because vocational interests in the Realistic area are related to spatial ability [14], we hypothesized that Realistic interests would show similar brain correlates to spatial ability $[3,4]$.

The four other areas of vocational interests (Artistic, Social, Enterprising, Conventional) have shown a lesser degree of relationship with cognitive abilities [8], and so we explored whether they would show any separate relationships with regional gray matter volume.

Like many neuroimaging studies, this one used a relatively small sample, and so it should be viewed as an exploratory investigation into the brain correlates of vocational interests. Because of the sample size, we did not examine sex differences.

\section{Analysis one: psychometric relationships}

We started by examining the relationships between interests and abilities in a large sample before we looked at the neuroimaging data in a smaller subset of subjects.

\section{Ethics statement}

Each participant gave written informed consent as approved by the Executive Committee of the Johnson O'Connor Research Foundation. This research was conducted in accord with the Helsinki Declaration.

\section{Subjects}

During 2006-07, 8,181 individuals sought consultation from the Johnson O'Connor Research Foundation (JOCRF), a nonprofit organization dedicated to using psychometric assessments for vocational guidance. Each completed a battery that included eight cognitive-ability tests and a vocational-interest measure (see below) in one of 11 testing offices in major cities throughout the United States. The mean age for all subjects was 24.9 years $(S D=10.8$ ); there were 4,438 males (mean

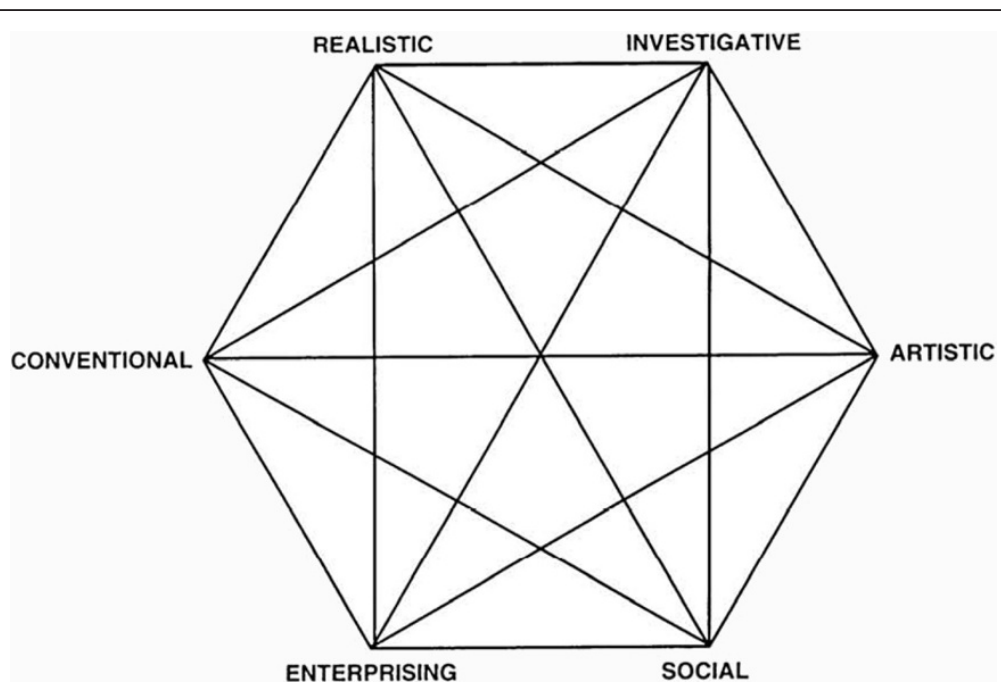

Figure 1 Holland's hexagon model for vocational interests. 
Table 2 Descriptive statistics for samples

\begin{tabular}{|c|c|c|c|c|}
\hline \multirow[b]{2}{*}{ Measure } & \multicolumn{2}{|c|}{ Study one $(N=8,181)$} & \multicolumn{2}{|c|}{ Study two $(N=40)$} \\
\hline & $M$ & $S D$ & $M$ & SD \\
\hline \multicolumn{5}{|l|}{ Self-directed search } \\
\hline Realistic & 20.03 & 10.30 & 19.65 & 7.96 \\
\hline Investigative & 22.95 & 9.99 & 24.80 & 9.99 \\
\hline Artistic & 23.71 & 10.79 & 25.88 & 9.22 \\
\hline Social & 27.21 & 9.29 & 27.33 & 9.69 \\
\hline Enterprising & 26.54 & 9.79 & 28.05 & 9.82 \\
\hline Conventional & 18.75 & 8.75 & 22.15 & 6.56 \\
\hline \multicolumn{5}{|l|}{ Cognitive abilities } \\
\hline \multicolumn{5}{|l|}{ Spatial } \\
\hline Wiggly block & 277.49 & 99.27 & 320.35 & 88.60 \\
\hline Paper folding & 22.49 & 13.86 & 28.73 & 14.68 \\
\hline \multicolumn{5}{|l|}{ Numerical } \\
\hline Number series & 23.71 & 4.58 & 24.48 & 4.98 \\
\hline Number facility & 94.79 & 17.34 & 100.66 & 19.38 \\
\hline \multicolumn{5}{|l|}{ Memory } \\
\hline $\begin{array}{l}\text { Verbal-associative } \\
\text { memory }\end{array}$ & 21.54 & 9.74 & 24.40 & 10.14 \\
\hline Number memory & 81.72 & 28.68 & 91.55 & 28.17 \\
\hline \multicolumn{5}{|l|}{ Speed of reasoning } \\
\hline Inductive speed & 141.50 & 22.58 & 141.15 & 22.22 \\
\hline Analytical reasoning & 54.83 & 12.79 & 60.32 & 14.20 \\
\hline
\end{tabular}

Note. The reported values are for raw scores unpartialled for sex, age, or $g$. The Study Two sample scored significantly higher than the Study One sample on Wiggly Block, Paper Folding, Number Facility, Number Memory, and Analytical Reasoning $(p<.05)$. The two groups did not differ significantly on any of the interest measures except for Conventional, on which the Study Two sample scored about 4 of a standard deviation higher than the Study One sample.

age $=24.2, S D=10.0$ ) and 3,743 females (mean age $=$ 25.8, $S D=11.6)$.

\section{Vocational-interest measure}

We measured six vocational interest areas with Holland's Self-Directed Search (SDS) [15]. As noted, these areas are described in Table 1 and the hexagon model shown in Figure 1.

\section{Cognitive-ability measures}

Eight tests from the Johnson O'Connor battery were given: Inductive Speed (IS), Analytical Reasoning (AR), Number Series (NS), Number Facility (NF), Wiggly Block (WB), Paper Folding (PF), Verbal-Associative Memory (VAM), and Number Memory (NM). A description of these tests, including the constructs they measure and their reliabilities can be found in the Haier et al. article [4], along with confirmation that this battery loads on four group factors - Speed of Reasoning (IS and AR), Numerical (NS and NF), Spatial (WB and PF), and Memory (VAM and NM) in addition to a $g$-factor.
The means and standard deviations for all of the tests are shown in Table 2.

We computed standardized scores ( $z$-scores) for the eight tests and computed average $z$-scores for each factor. The general intelligence $g$-score for each subject was the average of their $z$-scores on the eight tests (see Haier et al. [4] for additional details) with an alpha reliability of .80. The $g$ and residualized (that is, $g$-partialled) $z$ scores for each factor were used to determine the correlations with the vocational interest scales. Note that residualized scores for speed of reasoning, numerical, spatial, and memory represent participants' performance not shared with the general factor score $(g)$. Test scores on both the interest and ability measures were partialled for sex and age in order to eliminate nuisance variance.

\section{Results}

The correlations between the six SDS scales and the Johnson O'Connor ability factors are shown in Table 3. As can be seen, the correlations are generally modest. The largest correlation $(r=.41)$ is between $g$ and Investigative interests. There is also a moderate correlation (.30) between Realistic interests and the Spatial factor (again, with $g$ partialled out). These results support our particular focus on brain areas related to both Realistic interests and Spatial ability and to Investigative interests and general ability.

\section{Analysis two: imaging \\ Ethics statement}

In addition to the JOCRF consent described above, each participant for this portion of the study gave written informed consent for the imaging research described below, as approved by the Mt. Sinai Medical Center Institutional Review Board. This research was conducted in accord with the Helsinki Declaration.

Table 3 Correlations between SDS scales and JOCRF ability factors $(\mathrm{N}=\mathbf{8 , 1 8 1})$

\begin{tabular}{llllll}
\hline \multicolumn{5}{c}{ Ability factor } \\
\hline SDS scale & 9 & Spatial & Numerical & Memory & Speed of reasoning \\
Realistic & .14 & .30 & -.19 & -.16 & .04 \\
Investigative & .41 & .07 & .03 & -.05 & -.06 \\
Artistic & .08 & .02 & -.12 & .05 & .04 \\
Social & -.03 & -.14 & .05 & .05 & .05 \\
Enterprising & .01 & -.11 & .09 & .01 & .02 \\
Conventional & .15 & -.07 & .16 & .01 & -.08 \\
\hline
\end{tabular}

Note. All correlations greater than .02 (or less than -.02) are significant at the $p=.01$ level. For the ability factors, each factor other than $g$ was partialled for $g$. 
Table 4 Gray matter correlates of investigative Interest scores and overlap of investigative and JOCRF $\mathrm{g}$ correlates $(\mathbf{N}=\mathbf{4 0})$

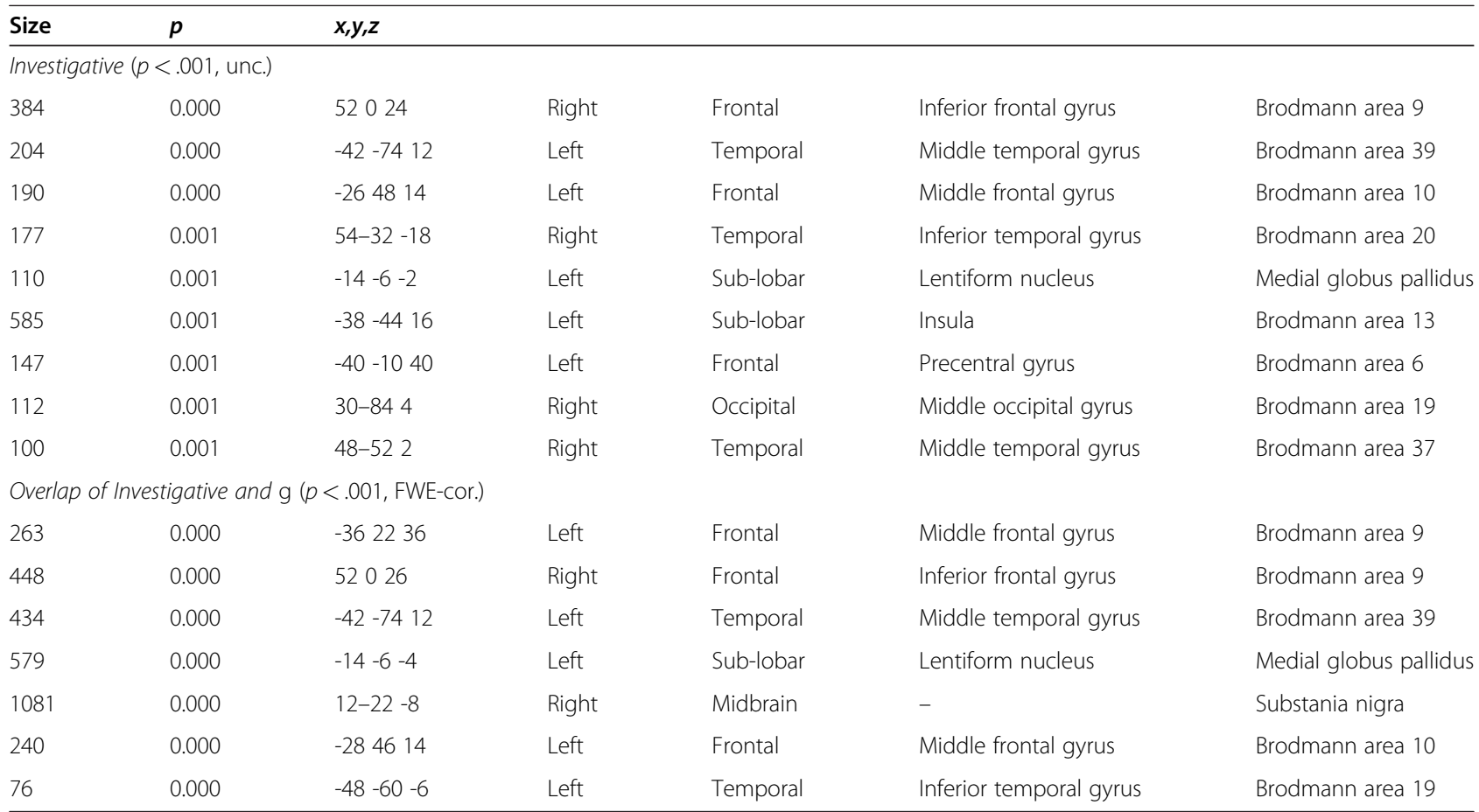

Note. All correlations are positive; size is number of voxels in significant cluster; $p$ for Investigative correlates is uncorrected; $p$ for overlap correlates is FWEcorrected; $x, y, z$ coordinates are maximum voxel (MNI); left/right is hemisphere; Brodmann areas are best estimates from Talairach and Tournoux Atlas (1988).

\section{Subjects}

The subjects are a subset of those in the above analysis and the same as those described in several previous reports $[4,11,12]$. Subjects between the ages of 18 and 35 who completed the test battery in the New York City office were invited to return for MRI scanning at Mt. Sinai Medical Center. All who volunteered were screened for medical and psychiatric illnesses including a history of head injury and substance abuse. 40 subjects consented and completed MRI (21 males and 19 females, with a mean age of $26.6, S D=4.9)$. They all completed the same battery of ability tests and the SDS, as described above.

The means and standard deviations for this sample on the interest and ability scales are shown in Table 2 . The distributions for this sample are fairly similar to the distributions for the larger JOCRF sample. The means are somewhat higher than for the larger sample on the ability scales, but the standard deviations are similar, which indicates sufficient variation to support correlation analyses.

\section{Structural MRI acquisition}

A 3T Siemens Allegra MRI scanner (Siemens Medical Systems, Erlangen, Germany) was used at Mt. Sinai Medical Center, NYC. For each subject, a sagittal $\mathrm{T}_{1^{-}}$ weighted spin echo image was performed first as localizer. Based on this localizer, structural scans were acquired using a 3D MP-RAGE pulse sequence with the following parameters: $\mathrm{TR}=2500 \mathrm{~ms}$, $\mathrm{TE}=4.4 \mathrm{~ms}$, $\mathrm{FOV}=$ $21 \mathrm{~cm}$, matrix size $=256 \times 256,208$ slices with thickness $=0.82 \mathrm{~mm}$.

Voxel-based-morphometry (VBM) and statistical analyses Using Statistical Parametric Mapping software (SPM5; The Wellcome Department of Imaging Neuroscience, University College London), we applied voxel-based morphometry (VBM) to identify brain areas where gray matter (GM) volumes are correlated with test scores. The structural images were bias field corrected, and segmented using an integrated generative model (unified segmentation, [16]). Unified segmentation involves alternating between segmentation, bias field correction, and normalization to obtain local optimal solutions for each process. The default SPM5 tissue probability maps were used (tissue probability maps provided by the International Consortium for Brain Mapping T1 452 Atlas [17]). The final segmentations were modulated [18] and GM partitions were smoothed with a 12-mm FWHM isotropic Gaussian kernel to account for slight misalignments of homologous anatomical structures and to ensure statistical validity under parametric assumptions.

To identify areas where GM correlated to SDS scales, we used a significance level of $p<.001$ uncorrected in 
Table 5 Gray matter correlates of realistic interest scores and overlap of realistic and JOCRF spatial correlates $(\mathrm{N}=40)$

\begin{tabular}{|c|c|c|c|c|c|c|}
\hline \multirow{2}{*}{\multicolumn{2}{|c|}{$\frac{\text { Size }}{\text { Realistic }(p<.001, \text { unc. })}$}} & \multicolumn{5}{|l|}{$x, y, z$} \\
\hline & & \multirow[b]{2}{*}{$8-1434$} & \multirow[b]{2}{*}{ Right } & \multirow[b]{2}{*}{ Limbic } & \multirow[b]{2}{*}{ Cingulate gyrus } & \multirow[b]{2}{*}{ Brodmann area 23} \\
\hline 7031 & 0.000 & & & & & \\
\hline 1177 & 0.000 & -342040 & Left & Frontal & Precentral gyrus & Brodmann area 9 \\
\hline 300 & 0.000 & $-30-2240$ & Left & Parietal & Postcentral gyrus & Brodmann area 3 \\
\hline 1142 & 0.000 & $72-36-18$ & Right & Temporal & Middle temporal gyrus & Brodmann area 21 \\
\hline 100 & 0.000 & -184814 & Left & Frontal & Medial frontal gyrus & Brodmann area 10 \\
\hline 210 & 0.001 & $-28-76-6$ & Left & Occipital & Lingual gyrus & Brodmann area 19 \\
\hline 802 & 0.001 & 34-18 46 & Right & Frontal & Precentral gyrus & Brodmann area 4 \\
\hline 255 & 0.001 & 64204 & Right & Frontal & Inferior frontal gyrus & Brodmann area 45 \\
\hline 2479 & 0.001 & $8-70-38$ & Right & Posterior & Uvula & - \\
\hline 283 & 0.001 & -201014 & Left & Sub-lobar & Lentiform nucleus & Putamen \\
\hline \multicolumn{7}{|c|}{ Overlap of Realistic and Spatial factor ( $p<.001$, FWE-cor.) } \\
\hline 206 & 0.000 & -321442 & Left & Frontal & Middle frontal gyrus & Brodmann area 8 \\
\hline 147 & 0.000 & $8-1636$ & Right & Limbic & Cingulate gyrus & Brodmann area 24 \\
\hline 423 & 0.000 & -18614 & Left & Sub-lobar & Lentiform nucleus & Putamen \\
\hline 179 & 0.000 & 22218 & Right & Sub-lobar & Lentiform nucleus & Putamen \\
\hline 479 & 0.000 & $-28-22-6$ & Left & Sub-lobar & Lentiform nucleus & Putamen \\
\hline 359 & 0.000 & $36-2070$ & Right & Frontal & Precentral gyrus & Brodmann area 6 \\
\hline 85 & 0.000 & 302438 & Right & Frontal & Middle frontal gyrus & Brodmann area 9 \\
\hline 160 & 0.000 & 61630 & Right & Limbic & Cingulate gyrus & Brodmann area 24 \\
\hline 54 & 0.000 & 345238 & Right & Frontal & Superior frontal gyrus & Brodmann area 9 \\
\hline 77 & 0.001 & $-5628-10$ & Left & Frontal & Inferior frontal gyrus & Brodmann area 47 \\
\hline 600 & 0.001 & -363434 & Left & Frontal & Superior frontal gyrus & Brodmann area 9 \\
\hline
\end{tabular}

Note. All correlations are positive; size is number of voxels in significant cluster; $p$ for Realistic is uncorrected; $p$ for overlap correlates is FWE-corrected; $x, y, z$ coordinates are maximum voxel (MNI); left/right is hemisphere; Brodmann areas are best estimates from Talairach and Tournoux Atlas (1988).

view of the small sample size and the exploratory nature of this study. To test the two hypotheses, we determined overlap between I and the $g$-factor, and between $\mathrm{R}$ and the spatial factor, as described previously [4] using the $x j$-view tool from SPM5, with $p<.05$ for each scale; we report only overlap areas significant at $p<.001$ corrected using FWE (family wise error). Xjview overlays multiple statistical images on top of each other to show statistical overlap for the images. If each of two analyses is thresholded at $p<.05$ uncorrected, the resulting image will have a threshold which is multiplicative. Thus $p<.05 \mathrm{X} p<.05=p<.0025$. The result is a conjunction of the analyses, or the probability of the independent results overlapping in a particular brain region. For Tables 4 and 5 and Figures 2 and 3, the probability of the correlates of interest overlapping in the brain regions indicated reaches the FWE threshold of $p<.001$ even though each individual analysis does not reach that threshold, so more significant regions are identified. Also, more regions appear significant at $p<.001$ FWE corrected in Table 5 because the areas covered by the overlap are smaller (fewer voxels) and thus one region which covered a large area in the original analysis is broken up into multiple regions.

\section{Results}

Positive GM correlates of the Investigative (I) scale are shown in Figure 2 (top) and detailed in Table 4 ( $p<.001$ uncorrected). Nine areas were found including large clusters in Brodmann Areas (BA) 9, 10, 13, 39 and the globus pallidus. There were two small clusters where the correlations were negative (BA 7 and 38; with only 82 and 27 voxels, respectively). None of these correlations survived FWE correction.

The overlap of these areas with areas related to $g$ is shown in the bottom of Figure 2 and detailed in Table 4. Using FWE corrected values at $p<.001$, the main overlap areas were BA 9, 39 and the globus pallidus.

GM correlates of the Realistic (R) scale are shown in Figure 3 (top panel) and detailed in Table $5(p<.001$, 

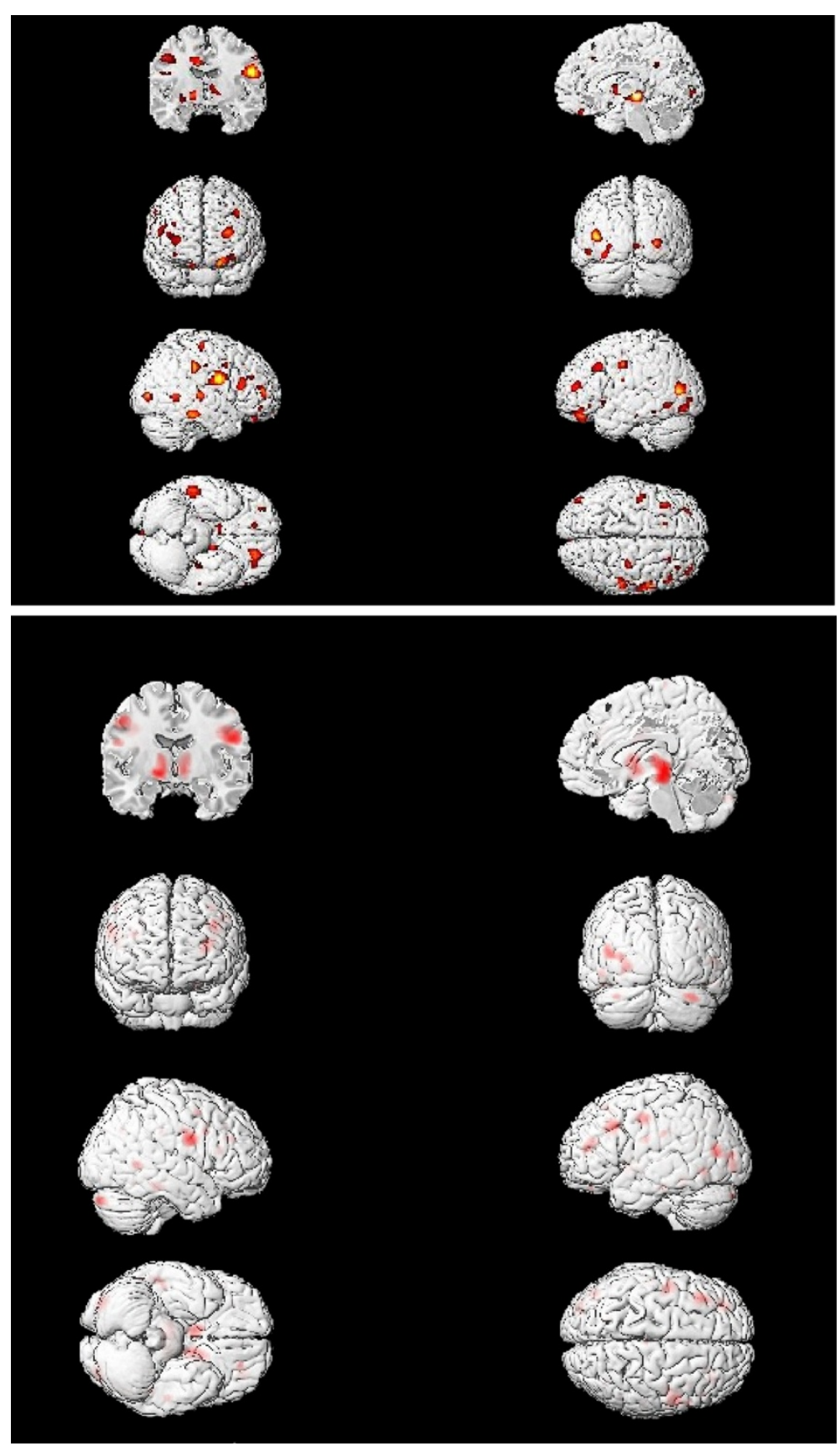

Figure $\mathbf{2}$ Gray matter correlates of Investigative interests and overlap of correlates of Investigative and $\boldsymbol{g}$. Gray matter correlates (positive) of Investigative interest scores (top panel), $N=40$ ( $p<.01$ yellow, $p<.025$ orange, $p<.05$ red); and overlap of Investigative and JOCRF $g$ correlates (bottom panel; $p<.001 \mathrm{FWE})$

uncorrected). GM is positively correlated with $\mathrm{R}$ in a number of brain areas. In particular, there is a large cluster that includes portions of the cingulate gyrus in BA 23, and there are good-sized clusters in BA 4, 9, 21, and the uvula lobe in the cerebellum. The overlap with the spatial factor is shown in the bottom panel of Figure 3 and detailed in Table 5. Main overlap areas include BA 8,24 , and the putamen.

To help visualize the overlap results, Additional file 1: Figure S1 and Additional file 2: Figure S2 show the VBM correlates of the interest scales and the cognitive-ability scores, both at $p<.05$. 

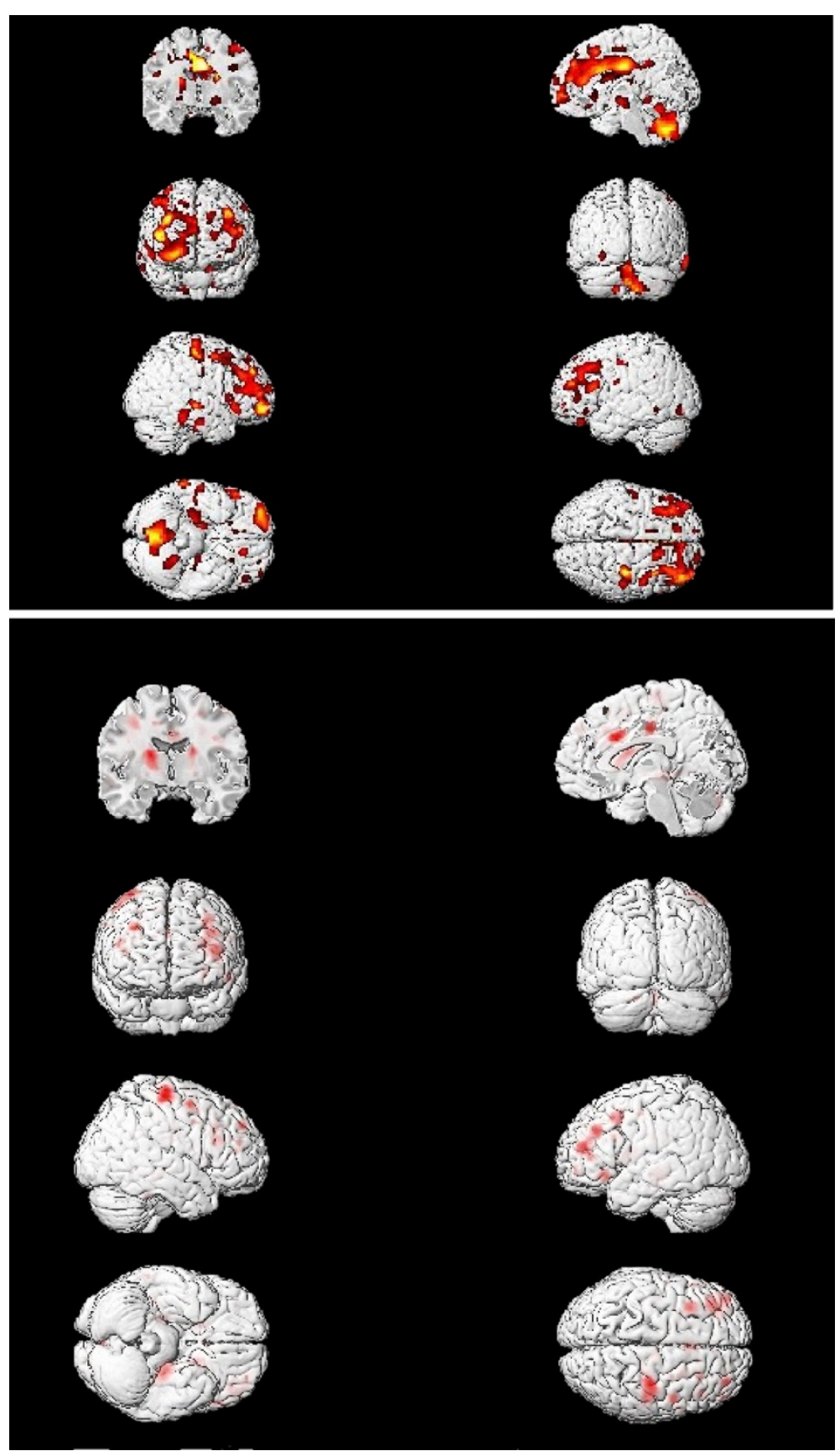

Figure 3 Gray matter correlates of Realistic interests and overlap of correlates of Realistic and spatial ability. Gray matter correlates (positive) of Realistic interest scores (top panel), $N=40$ ( $p<.01$ yellow, $p<.025$ orange, $p<.05$ red); and overlap of Realistic and JOCRF Spatial correlates (bottom panel; $p<.001$ FWE)

In contrast, there were only a few small sporadic GM correlates of the other four interest scales at $p<.001 \mathrm{un-}$ corrected (not shown).

\section{Discussion}

As noted, our intention in this exploratory study is to introduce imaging techniques to the study of individual differences in vocational interests. Our findings from Analysis One demonstrate there are associations between two interest scales ( $\mathrm{I}$ and R) and two cognitive abilities ( $g$ and spatial factors). Furthermore, Analysis Two shows that, as hypothesized, there is overlap between GM in the respective brain areas for I and R interests and in areas related to the $g$ and spatial factors, 
respectively. Such relationships have not been identified previously.

It may be the case that I and $\mathrm{R}$ interests lead persons to invest time and effort into pursuits that benefit general intelligence and spatial ability, respectively. For example, a boy with realistic interests may play with Lincoln Logs and build model airplanes, and these activities may foster the development of visualization ability in a manner akin to the development of crystallized intelligence in Cattell's investment theory [19]. On the other hand, it is possible that spatial ability and general intelligence lead to positive experiences with outdoor and scientific endeavors, which then lead to interests in Realistic and Investigative areas, respectively [7].

Although our data do not speak to the direction of effect, the Investigative and Realistic interest scales were the two that showed relationships with brain structure. Because of the small sample size, results based on VBM must not be overinterpreted, so we are only commenting on results relevant to our hypotheses regarding overlap of brain areas for these interest scales and the two ability factors that reach significance with FWE correction. The I scale overlap with the $g$-factor (Table 4) is mostly in prefrontal association (BA 9, 10) and parietal/temporal areas (BA 39) and the substania nigra. All but the latter have been associated with general intelligence previously across several studies [1]. The $\mathrm{R}$ scale overlap with the spatial factor (Table 5) is mostly in frontal areas (BA 6, $8,9,47)$ along with the putamen and a part of the cingulate gyrus. Although spatial ability is often associated with the right hemisphere, we find areas in both hemispheres, possibly due to idiosyncrasies in our sample. Note also that this set of overlap areas is larger than those associated with just spatial ability here and in our 2009 [4] and 2010 papers [11] because of the multiplicative nature of the xj view analysis as explained earlier.

Our data suggest that individual differences in I and $R$ vocational interests may be attributable to brain differences in areas related to general intelligence and spatial ability, respectively. For the other four vocationalinterest scales, there was little relationship with cognitive-ability factors or brain structure. Interests in those areas may be influenced by temperament factors [7], which were not studied here, but if that is the case, one might have expected to see relationships with brain areas associated with temperament [6]. On the other hand, interests in these areas may be largely due to socialization and life experience, and these influences may be relatively independent of brain structure as measured here.

Finding brain correlates of any psychometric scale provides some validity for the scale. Our results suggest that some but not all vocational interests may reflect brain characteristics. How a characteristic like gray matter volume may develop, and how it may lead to individual differences related to vocations, is far from clear. This study demonstrates that neuro-imaging may help provide clues to these fundamental questions.

\section{Additional files}

Additional file 1: Figure S1. Gray matter correlates of Investigative interest scores (red) and JOCRF $g$ scores (blue), both shown at $p<.025$. Overlap is purple.

Additional file 2: Figure S2. Gray matter correlates of Realistic interest scores (red) and JOCRF Spatial scores (blue), both shown at $p<.025$. Overlap is purple.

\section{Competing interests}

This project was funded at the Mt. Sinai Medical Center (Cheuk Tang), New York City, by the nonprofit Johnson O'Connor Research Support Corporation (JOCRSC). Cheuk Tang received partial salary support, and Richard Haier is a paid consultant of the JOCRSC. David Schroeder is an employee of the Johnson O'Connor Research Foundation (JOCRF), which receives financial support from the JOCRSC. The JOCRSC did not have any approval or supervisory role in the preparation of the manuscript or the decision to publish.

\section{Acknowledgements}

The authors express appreciation to Chris Condon and Emily Eaves for invaluable help in data collection and preparation and to Kevin Head for VBM analyses.

\section{Author details}

'Johnson O'Connor Research Foundation, Chicago, IL, USA. ² University of California, School of Medicine (Emeritus), Irvine, CA, USA. ${ }^{3}$ Mt. Sinai Medical Center, School of Medicine, New York City, USA.

\section{Authors' contributions}

$\mathrm{RJH}$ and DHS conceived and designed the study. CYT collected the imaging data. DHS and RJH analyzed the data. All authors approved and helped write the manuscript.

Received: 6 October 2011 Accepted: 25 April 2012

Published: 16 May 2012

\section{References}

1. Jung RE, Haier RJ: The Parieto-Frontal Integration Theory (P-FIT) of intelligence: Converging neuroimaging evidence. Behav Brain Sci 2007, 30:135-154.

2. Deary IJ, Penke L, Johnson W: The neuroscience of human intelligence differences. Nat Rev Neurosci 2010, 11:201-211.

3. Colom R, Haier RJ, Head K, Alvarez Linera J, Angeles Quiroga M, Chun Shih $P$, Jung RE: Gray matter correlates of fluid, crystallized, and spatial intelligence: Testing the P-FIT model. Intelligence 2009, 37:124-135.

4. Haier RJ, Colom R, Schroeder DH, Condon CA, Tang CY, Eaves E, Head K: Gray matter and intelligence factors: Is there a neuro-g? Intelligence 2009, 37:136-144.

5. Haier RJ: Brain imaging studies of personality: The slow revolution. In On the Psychobiology of Personality: Essays in Honor of Marvin Zuckerman. Edited by Stelmack RM. Amsterdam: Elsevier; 2004:329-340.

6. DeYoung CG, Hirsh JB, Shane MS, Papademetris X, Rajeevan N, Gray JR: Testing predictions from personality neuroscience: Brain structure and the Big Five. Psych Science 2010, 21:820-828.

7. Holland JL: Making Vocational Choices: A Theory of Vocational Personalities and Work Environments. 3rd edition. Lutz, FL: Psychological Assessment Resources, Inc; 1997.

8. Kelso Gl, Holland JL, Gottfredson GD: The relation of self-reported competencies to aptitude test scores. J Vocat Behav 1977, 10:99-103.

9. Larson LM, Rottinghaus PJ, Borgen FH: Meta-analyses of Big Six interests and Big Five personality factors. J Vocat Behav 2002, 61:217-239. 
10. Holland JL, Fritzsche BA, Powell AB: The Self-Directed Search (SDS) technical manual. 1994 edition. Lutz, FL: Psychological Assessment Resources, Inc; 1994.

11. Haier RJ, Schroeder DH, Tang CY, Head K, Colom R: Gray matter correlates of cognitive ability tests used for vocational guidance. BMC Research Notes 2010, 3(1):206.

12. Tang CY, Eaves EL, Ng JC, Carpenter DM, Kanellopoulou I, Mai X, Schroeder $\mathrm{DH}$, Condon CA, Colom R, Haier RJ: Brain networks for working memory and factors of intelligence assessed in males and females with $\mathrm{FMRI}$ and DTI. Intelligence 2010, 38:293-303.

13. Carson AD: The integration of interests, aptitudes, and personality traits: A test of Lowman's matrix. J Career Assessmt 1998, 6:83-105.

14. Carson AD: The relation of self-reported abilities to aptitude test scores: A replication and extension. J Vocat Behav 1998, 53:353-371.

15. Holland JL: Self-Directed Search Form R. 4th edition. Lutz, FL: Psychological Assessment Resources, Inc; 1994.

16. Ashburner J, Friston $\mathrm{KJ}$ : Voxel-based morphometry-the methods. Neuroimage 2000, 11:805-821.

17. Mazziotta JC, Toga AW: Tissue Probability Map Provided by the International Consortium for Brain Mapping (T1 452 Atlas)., [http://www. Ioni.ucla.edu/Atlases/Atlas_Detail.jsp?atlas_id=6].

18. Good CD, Johnsrude IS, Ashburner J, Henson RN, Friston KJ, Frackowiak RS: A voxel-based morphometric study of ageing in 465 normal adult human brains. Neuroimage 2001, 14:21-36.

19. Horn JL: A basis for research on age differences in cognitive abilities. In Human Cognitive Abilities in Theory and Practice. Edited by McArdle JJ, Woodcock RW. Mahwah, NJ: Lawrence Erlbaum; 1998:57-92.

doi:10.1186/1756-0500-5-242

Cite this article as: Schroeder et al:: Regional gray matter correlates of vocational interests. BMC Research Notes 2012 5:242.

\section{Submit your next manuscript to BioMed Central and take full advantage of:}

- Convenient online submission

- Thorough peer review

- No space constraints or color figure charges

- Immediate publication on acceptance

- Inclusion in PubMed, CAS, Scopus and Google Scholar

- Research which is freely available for redistribution 